\title{
A DESCRIPTION OF \\ THE LARVA OF THYCE HARFORDI CASEY (SCARABAEIDAE: MELOLONTHINI)
}

\author{
By Terry L. Erwin \\ Museum of Comparative Zoology
}

Mating flights of Thyce harfordi Casey adults were first noticed in San Jose, California in 1962. In subsequent years many adult beetles were collected, but attempts to excavate larvae proved unsuccessful until J. Gordon Edwards, Richard Penrose, and I found two specimens. These were destroyed in the mail when we sent them to P. O. Ritcher at Oregon State University. The following year, Charles Baker, Toby Schuh, Edwards, and I returned to the cherry orchard the larvae were taken from previously. This trip in May, 1965, proved successful in our search for one of the few large scarab genera with undescribed immature stages.

Five or six excavations were made, each one adjacent to a randomly chosen cherry tree. The holes were dug to a depth of six feet and were from five to eight feet square. Even with this amount of digging, only eleven larvae were found (two were so badly damaged by the shovel that they had to be discarded).

These larvae are here described and a key (for larvae) to the known genera of the Tribe Melolonthini is offered. For the most part, I have tried to follow the style and format used by Ritcher (1966) in order to make this single description fit into that author's excellent and recent work on white grubs and their allies.

\author{
Tribe Melolonthini (sensu Ritcher) \\ Key to genera with known immature stages, third instar \\ I. Palidia present (fig. 5) ............................................. 2 \\ I'. Palidia absent ..................... (in part) Phyllophaga Harris
}

Figs. 1-7. Thyce harfordi Casey. 1a. Head capsule, frontal aspect. 1b. Ultimate and penultimate antennal articles, proximal aspect. 2. Abdominal spiracle, 4th segment left side. 3a. Prothoracic leg, left lateral aspect. 3b. Prothoracic claw, caudal aspect. 4a. Left maxilla, dorsal aspect. 4b. Maxillary stridulatory teeth of left maxilla, dorsal aspect. 5. Raster, ventral aspect. 6a. Left mandible, dorsal aspect. 6b. Right mandible, dorsal aspect. 7. Epipharynx, proximal aspect. Symbols used: cpa, chaetoparia; $\mathrm{dp}$, dexiophoba; h, heli; lu, unci of lacinia; pe, pedium; pl, plegmata; pla, palidium; sd, maxillary stridulatory area. 


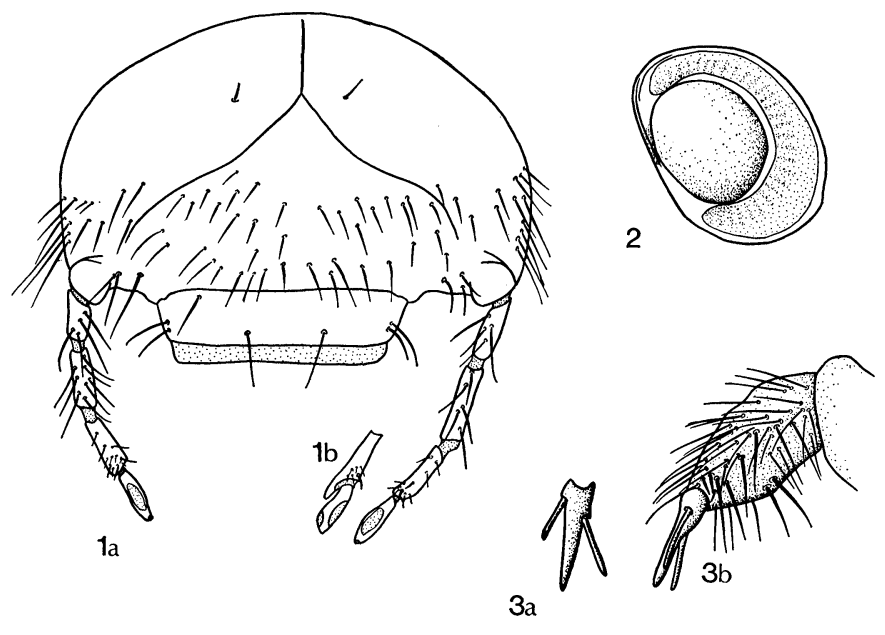

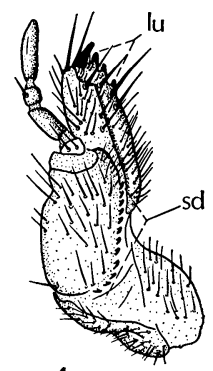

$4 a$

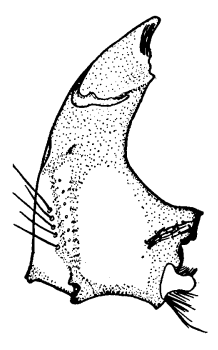

$6 a$

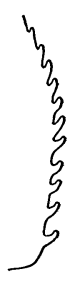

$4 b$

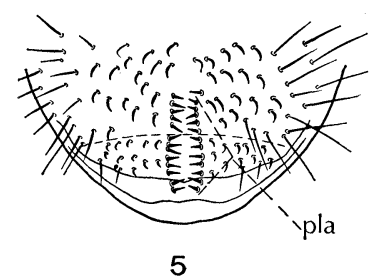

5

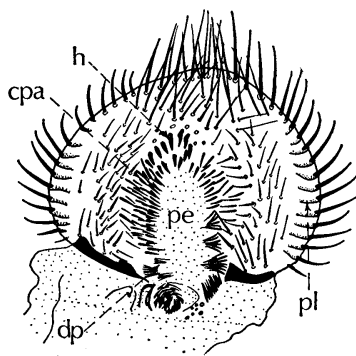

7 
2( I). Epipharynx with epizygum (sclerotized strip or patch near apex).

2'. Epipharynx without epizygum

3(2). Plegmata (fig. 7) short, not approaching outer chaetoparia; maxillary stridulatory teeth pointed .... Amphimallon Berthold

$3^{\prime}$. Plegmata long, closely approaching outer chaetoparia; maxillary stridulatory teeth truncate

(in part) Phyllophaga Harris

$4\left(2^{\prime}\right)$. Dexiophoba (fig. 7) ringing much of right side of pedium; maxilla (fig. 4a) with a row of $\mathrm{I} 4$ or more long, conical stridulatory teeth; haptomerum (fig. 7) with a group of 15 or more heli

Polyphylla Harris

$4^{\prime}$. Dexiophoba short; maxilla with a row of $12-13$ short, conical arcuate stridulatory teeth; haptomerum with a group of I4 heli (proximal ones small, setae-like)

Thyce LeConte

Genus Thyce LeConte, Third Instar Larva

The larvae of this genus are extremely similar to those of Poly phylla Harris. This similarity may indicate the monophyly of the two taxa which are retained as good genera on the basis of the adult antennal characteristics.

The following combination of characteristics is diagnostic of the larvae of the genus Thyce: Head without eye spots. Frons and gena with numerous scattered setae, lateral ones long. Labrum symmetrical. Epipharynx with epizygum; zygum indistinct. Haptomerum with a group of $\mathrm{I}_{4}$ heli. Plegmatia present, plegmata short. Proplegmatia absent. Dexiophoba short. Haptolachus with microsensilla. Maxilla with a row of I2-I3 short, conical, arcuate stridulatory teeth. Lacinia with longitudinal row of 3 stout unci. Anal slit transverse, ventral anal lobe not cleft. Raster with 2 short, longitudinal, parallel palidia. Preseptular hamate setae numerous, lateral setae long. Claws of prothoracic and mesothoracic legs long and falcate, those of mesothoracic legs slightly smaller. Claws of hind legs minute.

\section{Thyce harfordi Casey, Third Instar Larva (Figs. I-7)}

Material. Eleven specimens of third instar larvae found in pupal chambers and burrows beneath cherry trees, 2555 Meridian Avenue, San Jose, California, May, I965; collected by Charles Baker, Toby Schuh, J. Gordon Edwards and me. Two specimens taken by Baker to Oregon, both subsequently reared by $\mathrm{P}$. O. Ritcher to the adult stage. Both were females of Thyce harfordi. 
Description. The following combination of characteristics is dagnostic of the larvae of this species: Maximum width of head capsule 7.0 to $7.3 \mathrm{~mm}$. Head yellowish-brown in color, smooth, shiny. Haptomerum of epipharynx with I4 heli. Epipharynx without proplegmatia, the area covered instead with setae. Each plegmatium with I I-I 2 short plegmata. Haptolachus with seven microsensilla. Maxilla with row of I2-I3 short, conical, arcuate stridulatory teeth. Thoracic spiracles slightly larger than spiracles on abdominal segments I-5, which are all similar in size. Spiracles on abdominal segments 6 to 8 progressively smaller. Anal slit transverse, slightly curved. Raster with 2 short, parallel, longitudinal palidia, each with I3 short, sharp, pali. Septula narrow. Tegilla extending forward beyond the palidium for a distance equal to or slightly greater than half the length of the palidium. Preseptular setae more numerous than $5 \mathrm{O}$ (5O-IOO), adjacent lateral setae long.

Habitat. The specimens were found in the "B horizon," I 4 to 48 inches deep in sandy clay among the roots of cherry trees in what appeared to be an "old" orchard. The larvae found at I4 inches were upside down (supine) in pupal chambers, while the deeper ones were adjacent to the lower surface of roots of the cherry trees.

I would like to thank P. O. Ritcher and J. Gordon Edwards for critically reading this manuscript and offering suggestions.

RITCHER, P.O.

\section{Literature Cited}

1966. White grubs and their allies, a study of North American Scarabaeoid larvae. Oregon State University Press, Corvallis. 219 pp., 501 figs. 

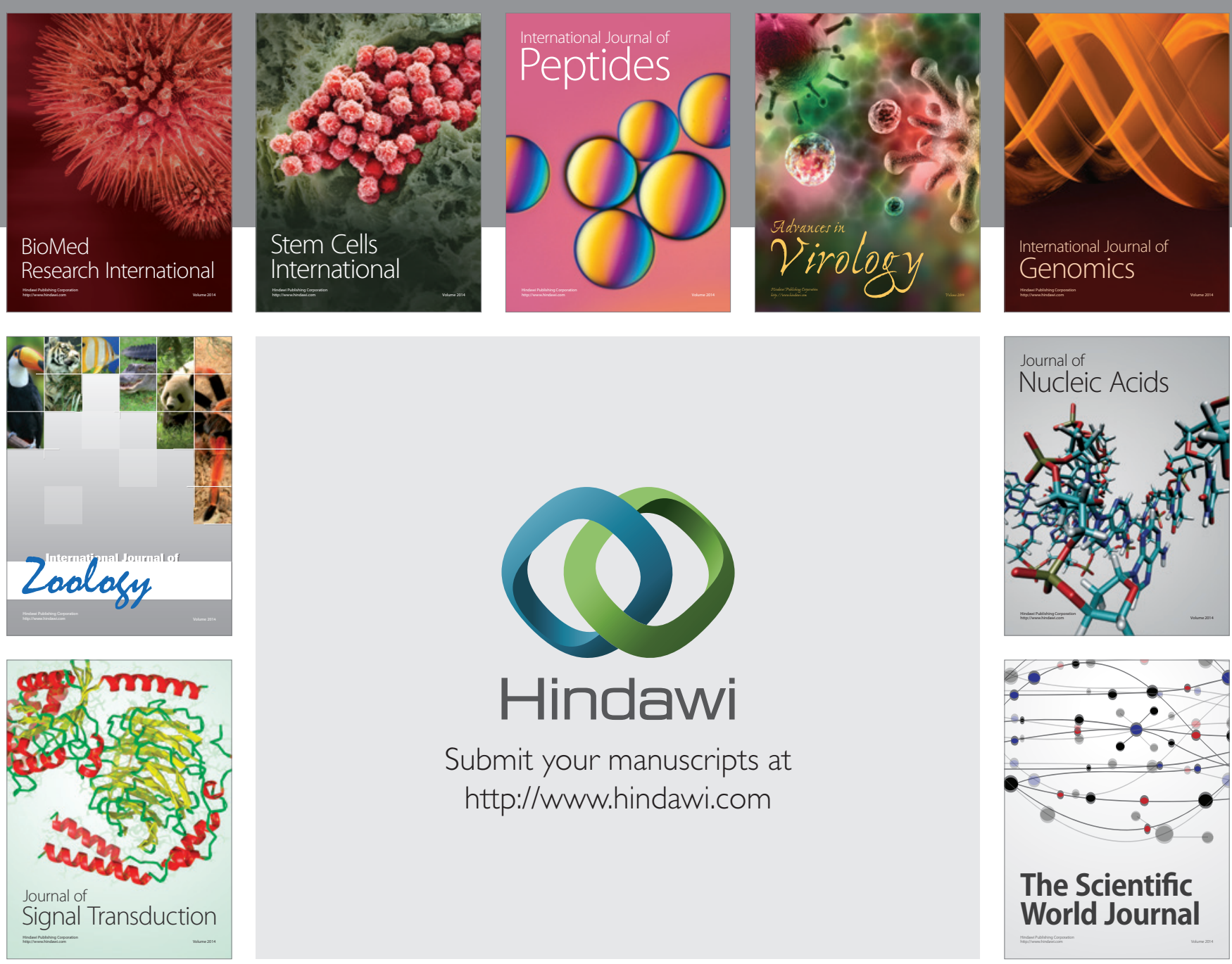

Submit your manuscripts at

http://www.hindawi.com
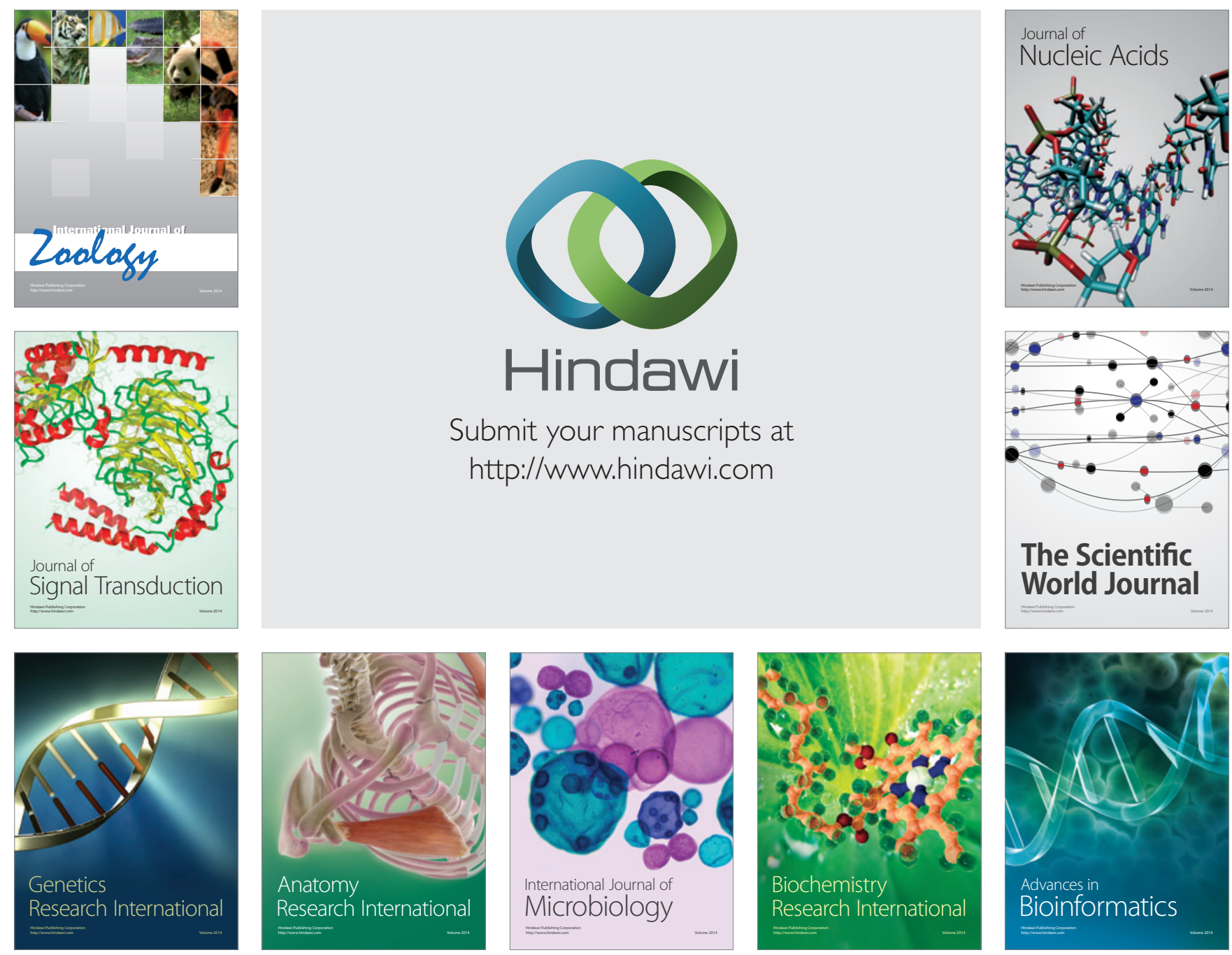

The Scientific World Journal
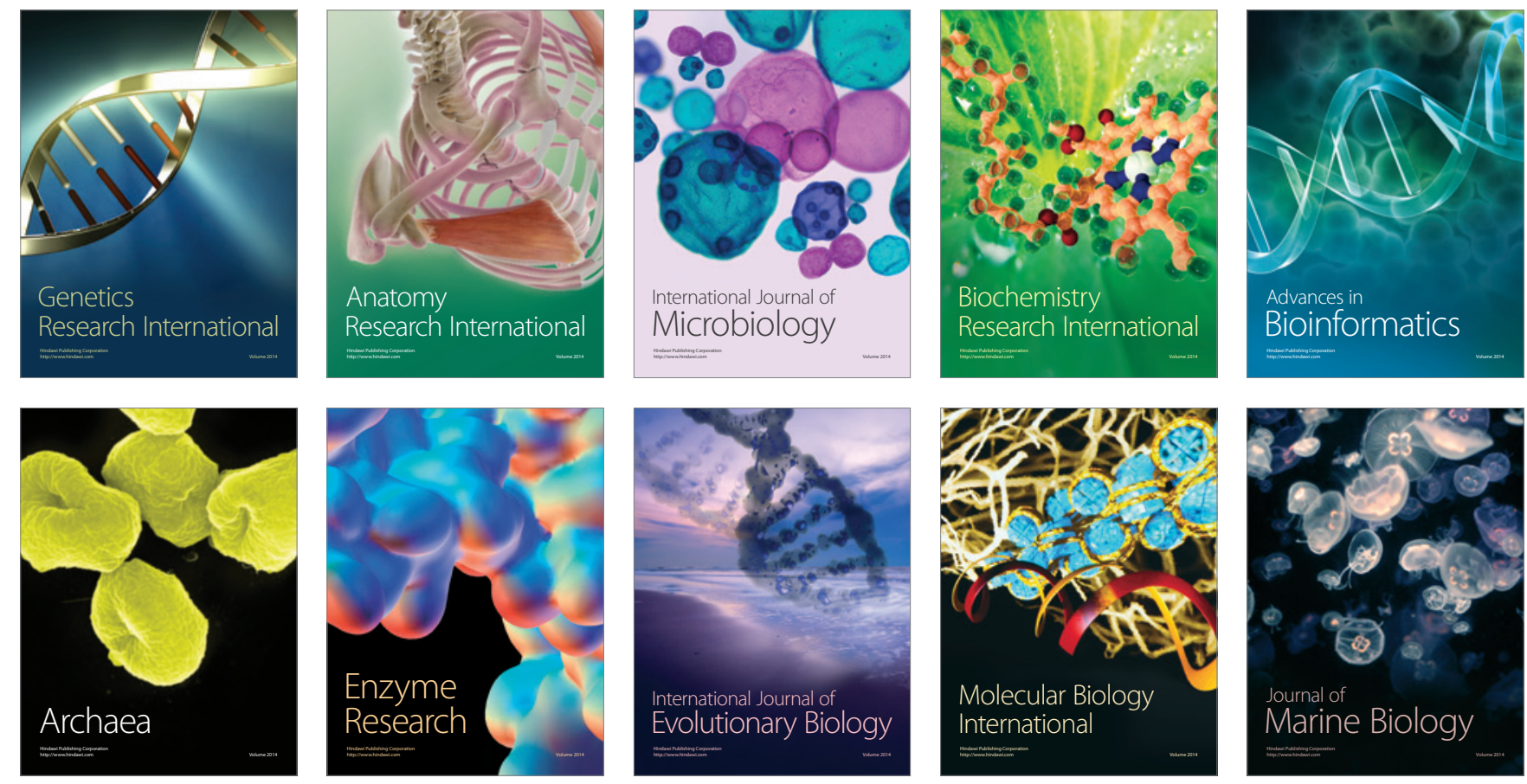